\title{
A CASE OF PROBABLE ENCEPHALITIS DUE TO THE INHALATION OF THE FUMES OF GASOLINE ${ }^{1}$
}

\author{
By Chas. S. Potts, M.D.
}

\begin{abstract}
PROFESSOR OF NEUROLOGY IN THE MEDICO-CHIRURGICAL COLLEGE OF PHILADELPHIA; NEUROLOGIST TO THE PHILADELPHIA GENERAL HOSPITAL
\end{abstract}

The production of more or less transient toxic symptoms such as headache, nausea, delirium and loss of consciousness by inhaling the fumes of gasoline is not uncommon. The production of more permanent symptoms referable to the nervous system is apparently not very common when the few cases of such that have been reported and the large quantities of gasoline now used are considered. Gasoline as sold contains a number of the different products of petrol distillation, such as naphtha, benzine and petroleum ether. The amount of these different hydrocarbon's in commercial gasoline is not fixed, but differs in that of different manufacturers. D. Felix ${ }^{2}$ in 1872 studied the effects of the inhalation of both benzine and petroleum ether and found that each caused vertigo, nausea, sleepiness, injection of the conjunctiva, burning pains in the chest and irritating cough. If the inhalation was continued loss of consciousness resulted. Oliver ${ }^{3}$ speaks of the inhalation of petrol causing headache, vertigo, vomiting and unconsciousness. He further says ${ }^{4}$ that inhalation of either benzine or naphtha will cause mental depression, hallucinations, loss of memory, blindness and multiple neuritis. Rambousek ${ }^{5}$ says that some naphtha products irritate the respiratory organs while others affect the central nervous system. The same author ${ }^{6}$ states that poisoning may occur from cleaning out petroleum stills and mixing vessels and in empting out residues, and occasionally from the use of benzine in chemical cleaning. He also speaks of the possibility of poisoning in the refining of naphtha from the inhalation of the vapor of the light oils, benzine and gasoline. Fatal cases have been recorded in badly ventilated work rooms in which

\footnotetext{
1 Patient shown to the Philadelphia Neurological Society. March 27, I9I4. Read by title at the fortieth annual meeting of the American Neurological Association, May 7, 8 and 9, I9I4.
} 
the products of distillation are collected. He mentions the case of a workman who had entered an open benzine still to scrape the walls free of crusts containing benzine. He was found unconscious and died some hours later. He mentions another case of a man who started to clean a benzine still. When he entered the opening he became unconscious and cyanosed, the pulse was weak, the legs were spastic and the reflexes absent. These symptoms disappeared ninety minutes later. Another man who examined the outlet of a petroleum tank had symptoms in two minutes. Gowers (quoted by Rambousek) reports a case of chronic poisoning following the frequent inhalation of gases given off from a petroleum motor. The symptoms were slurring speech, difficulty in swallowing, and weakness of the facial muscles. The symptoms disappeared when the man ceased his occupation but returned when he resumed it. Gowers believed the symptoms to be due to petroleum gas poisoning. In this connection it may be stated that among the waste products given off by a gasoline motor is carbon monoxide, such motors are therefore dangetous when running in a closed room. A case is reported ${ }^{8}$ in which two men who were in a garage with closed windows while the motor was running were found unconscious. One in addition was cyanosed, the pulse weak and rapid, the other was pale and had clonic spasms. Both recovered. The possibility of the conditions described by Dana, ${ }^{9}$ Spiller and McConnel1 ${ }^{10}$ and others occurring should be remembered when such exposure has occurted.

The case I report was a white male aged 45 years, who was admitted to the Medico-Chirurgical Hospital in an unconscious condition on November I4, I9I3. The history obtained at the time was that his occupation had been that of filling the tanks of automobiles with gasoline and while at work he had fallen over unconscious. He remained so for several hours and then passed into a stuporous condition which continued until November 25, when aroused from this he complained of intense headache. On admission his temperature was $97.4^{\circ} \mathrm{Fahr}$., the pulse 80 and the respiration 20. A few hours later the temperature was $97^{\circ} \mathrm{Fahr}$. and during the following three days dropped to that point several times, the pulse ranging from 72 to 90 . When admitted he was regarded as suffering from gasoline poisoning. He was transferred to my service on November 24, and was first seen by me on that date. He was still quite stupid but could be aroused. It was then noticed that there was ptosis of the right eyelid and that the eyeball was drawn downward and to the right. Some 
headache was complained of. The next day (November 25) the mental condition had much improved and he was examined by. Dr. Weisenburg, an abstract of his findings being as follows:

Nearly complete oculomotor palsy on the right side, the only movements present being a slight contraction of the pupil to light and slight power of raising the eyelid. On the left side the pupil was smaller than that of the right and responded to light, all movements of the eyeball were lost excepting inward rotation and slight rotation outward. The eyeball was turned in when at rest. Associated movement of both eyes to the right was present. The angle of the mouth could not be drawn as well to the left as to the right (facial palsy of central type) and the arm and leg of this side were much weaker than those of the right. The knee jerks were increased, the left the more so, ankle clonus was present on the left side and plantar irritation caused a tendency to dorsal flexion of the toes on the left. There was marked dysmetria on the left side, the finger, in the finger to nose test, usually going beyond the nose, the movement being quick and jerky. Adiadochokinesis was marked in the left arm. Asynergia of the left hand was well shown. The same conditions were present in the left leg, the heel to knee test being poorly performed, asynergia being present and the muscle tone less as shown by the fact that the thigh could be flexed upon the abdomen much more than on the right side. The station was very poor, the tendency being to fall to the left. The gait was very unsteady, of the cerebellar type, the tendency being to go to the left. The left leg was dragged slightly. All other functions of the nervous system were normal. On November 29, he was carefully examined by the writer, and the following additional facts were elicited: His family and previous history contained nothing of note. He had always been a hard worker, drank three or four glasses of beer daily, did not use tobacco and denied venereal disease, the Wassermann test was negative. He had worked at his present occupation for four months. Two months before admission he was seized one evening with intense headache, nausea and vomiting which lasted all night. He went to work in the morning however but since has had more or less severe headache and dizziness. During this period he began to see double, one image being to one side and above the other. The symptoms present were the same as those found on November 25, except that the ptosis of the left eyelid was somewhat less and the movements of the left eyeball while still sluggish, were better, upward and outward movement being the most impaired. Attempts to move the eyeballs caused coarse nystagmoid movements in the direction of the attempted movement. Ankle clonus had disappeared on the left side. The eye grounds were normal. . The functions of the viscera were normal. The treatment consisted at first of tinct. gentian co. as a placebo but was followed by iodide of potassium and strychnine. 
Improvement gradually took place and by February the only symptoms remaining were impairment of the functions of the left oculomotor nerve, ataxia of the left arm and possibly slight weakness of the left leg. These symptoms persisted and when last seen in April no further improvement had occurred. There would seem to be no doubt that the symptoms were due to a toxemia of some sort and that it was gasoline would seem to be a justifiable conclusion in view of the premonitory symptoms and the absence of exposure to any other form of poison. The question might be raised whether there was either merely a functional disturbance or an actual organic lesion as indicated by the diagnosis of encephalitis. The writer believes the latter to be justified, because while most of the symptoms have disappeared, there still, after a lapse of a number of months, remained evidence of permanent damage to some functions. The writer believes that a lesion in the region of the aqueduct of Sylvius would explain the symptoms.

In the discussion which followed the exhibition of the patient at the Philadelphia Neurological Society, the tendency of acute intoxications to cause cerebellar symptoms was commented upon.

\section{REFERENCES}

2. Vierteljahrschr. f. Öffentl. Ges.-Pfl., I872.

3. Diseases of Occupation, p. 85 .

4. Ibid., p. 83.

5. Josef Rambousek, Industrial Poisoning from Fumes, Gases and Poisons of Manufactuting Processes, translated by T. M. Legge, p. 6I.

6. Ibid., p. 62 et seq.

7. Pseudo-Myasthenia of Toxic Origin (Petrol Fumes). Review of Neurologyous Psychiatry, Jan. I908, p. I.

8. British Med. Jour., I908, Vol. I, p. 807 .

9. Jour. Nerv. and Mental Disease, Feb., Ig08, p. 65.

ro. Jour. Amer. Med. Assoc., Dec. I4, I912, p. 2122.

II. Jour. Nerv. ANd Mental Dis., I9I4, p. 527. 